\title{
LATERAL RELEASE FOR CHONDROMALACIA PATELLAE
}

\author{
A. H. OSBORNE, P. C. FULFORD
}

From the Orthopaedic Department, Royal Naval Hospital, Haslar, Gosport

\begin{abstract}
A series of 75 patients with established chondromalacia patellae is presented. All had a lateral release procedure carried out after failure of conservative treatment. The results are discussed in relation to the findings at operation. In the early stages of chondromalacia, release of the lateral retinaculum was successful in relieving the symptoms for a year or more; review at three years showed a significant number of relapses.
\end{abstract}

The term chondromalacia patellae was introduced by Aleman (1928), although it was Büdinger (1908) who first described fissures in the articular cartilage of the patella, which he considered to be traumatic in origin. Outerbridge (1961) defined four grades of severity in the changes found in the articular cartilage and these grades were used for assessment of this series. Grade 1 is localised softening, with swelling and fibrillation of articular cartilage; Grade 2 is fragmentation and fissuring in an area of 1.3 centimetres or less in diameter; Grade 3 is similar change in an area over 1.3 centimetres in diameter; and Grade 4 is erosion of the articular cartilage to expose subchondral bone.

A more appropriate clinical diagnosis for these patients when they first present is patellofemoral pain or pain in the front of the knee, the term chondromalacia patellae being reserved for definite macroscopic change seen on arthroscopy or at operation. The management of the energetic young man or woman who presents with patellar pain is difficult. Treatment varies from conservative measures relying mainly on rest, to a variety of operative procedures which will be discussed later.

\section{MATERIAL}

A series of 75 patients is presented, in whom a course of conservative treatment had failed to relieve symptoms (Table I). Sixty-six of these were young Royal Naval servicemen and women of whom 27 could relate their symptoms to a specific incident or particular activity, while another 18 deemed their symptoms to have followed a previous arthrotomy or meniscectomy. Examination of their case records suggested that most of these patients had made a slower than usual recovery from their initial operation. Two patients had previously undergone transfer of the tibial tubercle for patellar subluxation, and one had sustained a transverse fracture of the patella which had been treated conservatively and had healed with slight displacement. Seven patients could date their symptoms from a specific injury, and in one of them a lateral radiograph revealed an indentation of the femoral condyle caused by the patella. The other patients gave no specific cause for the onset of symptoms but all complained of pain during or after sporting activities or sea-going duties. The age of the patients varied from 15 to 31 years, with a mean of 21 years. Symptoms had been intrusive for from 6 to 48 months (mean 14 months) and Service personnel were usually operated on earlier then civilians in an endeavour to return them to full sea-going duties. The initial management was by rest, including complete cessation of sport and categorisation as unfit for sea-going duties, for one month during which ultrasonic therapy was given and static quadriceps exercises carried out. Any local tenderness at the margin of the patella was on occasion treated by local injection of hydrocortisone with lignocaine and Hyalase.

Patients with persisting symptoms were next treated in a Plastazote cylinder for a further month. Plaster cylinders have not been used since a Plastazote splint is more comfortable and can be taken off at night to allow a full range of movement to be maintained. Two-thirds of the patients orginally presented with some pain in both knees. Patients with acute bilateral symptoms were admitted to hospital for a period of bed rest with static quadriceps exercises and

Table I. Patients undergoing lateral release

\begin{tabular}{|c|c|c|c|c|c|c|c|c|c|}
\hline & & & Age & & $\begin{array}{r}\text { Durq } \\
\text { symptom }\end{array}$ & $\begin{array}{l}\text { of } \\
\text { months) }\end{array}$ & Number with & & \\
\hline $\mathbf{P a}$ & ents & Number & Range & Mean & Range & Mean & operations & Initial complic & \\
\hline Male & Service & 57 & $17-31$ & 23.5 & $6-30$ & 10 & 15 & $\begin{array}{l}\text { Haemarthrosis } \\
\text { Early pain }\end{array}$ & $\begin{array}{l}2 \\
5\end{array}$ \\
\hline & Civilian & 6 & $15-27$ & 20 & $12-48$ & 21 & 1 & - & \\
\hline Female & Service & 9 & $18-24$ & 20 & $6-36$ & 12 & 2 & Haemarthrosis & 1 \\
\hline & Civilian & 3 & $18-23$ & 19 & $9-30$ & 24 & 0 & - & \\
\hline & & 75 & $15-31$ & 21 & $6-48$ & 14 & 18 & 8 & \\
\hline
\end{tabular}

Surgeon Commander A. H. Osborne, MCh Orth, FRCS, FRCS Ed(Orth), RN, Senior Orthopaedic Specialist

Surgeon Captain Philip Fulford, CVO, OBE, MCh Orth, FRCS, RN, Consultant Orthopaedic Surgeon

Requests for reprints should be sent to Surgeon Commander A. H. Osborne, RN.

(1) 1982 British Editorial Society of Bone and Joint Surgery 0301-620X/82/2044-0202 \$2.00
Royal Naval Hospital, Haslar, Gosport, Hampshire PO12 2AA. England. 


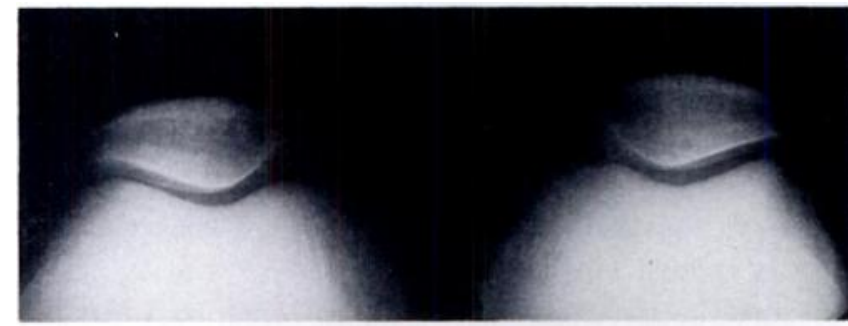

Fig. 1

Skyline radiographic views of both patellae to show lateral deviation. narrowing of the lateral joint space and early subchondral sclerosis in the left patella.

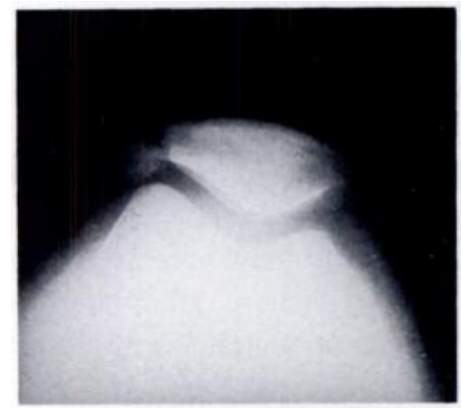

Fig. 2

Skyline radiograph to show a case of bipartite patella. Symptoms were relieved by a lateral release operation.

ultrasonic therapy. Radiographs, including skyline views, were taken of both knees. Most of these were normal, although evidence of increased lateral pressure and deviation of the patella (Fig. 1) (Ficat and Hungerford 1977) was noted in 11 patients, bipartite patella in six (Fig. 2) and patella alta in three (Marks and Bentley 1978). Osteophyte formation at the margin of the patella was present in four and cystic changes in two.

\section{METHODS}

According to Gray's Anatomy (1962) the iliotibial tract is a thickening of fascia lata which originates at the level of the greater trochanter by the condensation of three-quarters of the gluteus maximus and the whole of the tensor fascia lata. Its deep surface is continuous with the lateral intramuscular septum. At its lower end the tract is attached to the lateral condyle of the tibia and anteriorly to the lateral border of the patella, to form a lateral retinacular band of varying thickness. This band appears to tether the patella laterally on flexion and extension of the knee.

The operation was done through a three-centimetre incision. two centimetres from the lateral border of the patella. The capsule and synovium were incised and the posterior aspect of the patella inspected (Fig. 3). The articular surface was assessed and given an Outerbridge grade. The tightness and thickness of the lateral retinaculum was noted. Any flakes of loose cartilage were washed out. Lateral release of the extensor retinaculum was then carried out subcutaneously, using scissors, in a curved line from the vastus lateralis above to the tibial condyle below. The knee was flexed to 90 degrees to ensure thorough division with no residual tightness. Synovium and skin were closed with Dexon and a suction drain placed outside the synovium. Wool and crêpe bandages were applied. Suction drainage usually yielded 20 to 30 millilitres which increased to 200 to $\mathbf{3 0 0}$ millilitres on occasions when the retinacular division had been inadvertently carried upwards into the quadriceps muscle. In one such case the suction drain was dislodged soon after operation and a large haematoma tracked into the lower leg resulting in prolonged delay in recovery and ultimate failure.

Static quadriceps exercises were encouraged soon after operation and straight leg raising was allowed after 48 hours. After five days the dressing was taken down and replaced with Tubigrip. The patient was allowed up on crutches. Most patients left hospital six or seven days after operation. Mobilisation earlier than this sometimes resulted in a large effusion, which delayed recovery. Vigorous physiotherapy after operation tended to reactivate symptoms, and treatment was therefore restricted to static quadriceps exercises, straight leg raising without weights and the restoration of a full range of flexion and extension without resistance. Full knee bending under load was avoided and competition with patients who had had a meniscectomy was discouraged.

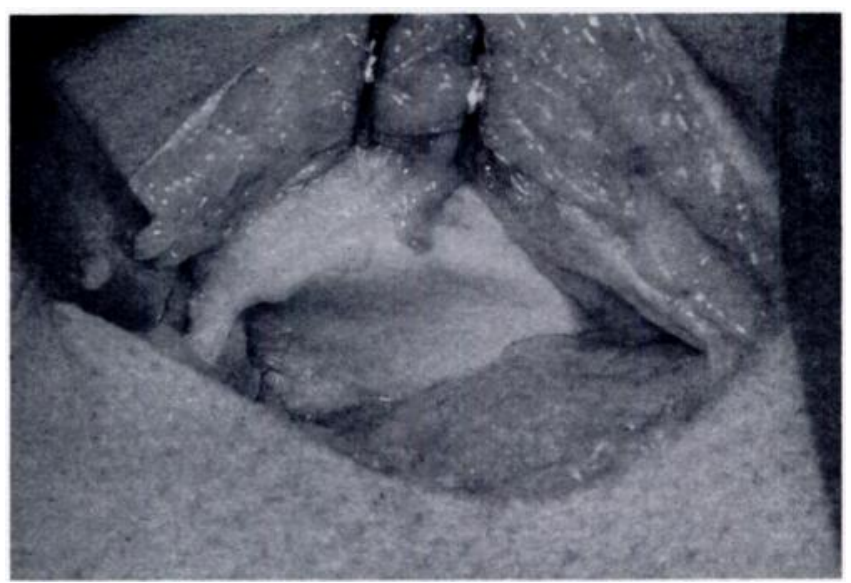

Fig. 3

View of the patella and synovium gained at a lateral release operation. The patella shows Outerbridge Grade 3 changes.

\section{RESULTS}

The findings and results at one year and at three years are detailed in Table II. Seventy patients in Outerbridge Grades 1 and 2 were placed in Group A. The other five patients with the more severe changes of Grades 3 and 4 were placed in Group B. Seventy-four patients were reviewed at one year and again at three years after lateral release for established chondromalacia patellae. The one patient who was not available for review was

Table II. Results by grades

\begin{tabular}{|c|c|c|c|c|c|c|c|c|c|c|c|c|c|}
\hline \multirow[b]{3}{*}{ Group } & \multirow[b]{3}{*}{ Sex } & \multirow[b]{3}{*}{ Number } & \multicolumn{4}{|c|}{ One year } & \multicolumn{6}{|c|}{ Three years } & \multirow[b]{3}{*}{$\begin{array}{l}\text { Further course } \\
\text { of poor results }\end{array}$} \\
\hline & & & \multicolumn{2}{|c|}{ Good } & \multicolumn{2}{|c|}{ Poor } & \multicolumn{2}{|c|}{ Good } & \multicolumn{2}{|c|}{ Fair } & \multicolumn{2}{|c|}{ Poor } & \\
\hline & & & Number & $\begin{array}{l}\text { Per } \\
\text { cent }\end{array}$ & Number & $\begin{array}{l}\text { Per } \\
\text { cent }\end{array}$ & Number & $\begin{array}{l}\text { Per } \\
\text { cent }\end{array}$ & Number & $\begin{array}{l}\text { Per } \\
\text { cent }\end{array}$ & Number & $\begin{array}{l}\text { Per } \\
\text { cent }\end{array}$ & \\
\hline $\begin{array}{l}\text { Group } A \\
\text { (Grades 1-2) }\end{array}$ & $\begin{array}{l}\text { Male } \\
\text { Female }\end{array}$ & $\begin{array}{l}58 \\
12\end{array}$ & $\left.\begin{array}{l}51 \\
10\end{array}\right\}$ & 87 & $\left.\begin{array}{l}7 \\
2\end{array}\right\}$ & 13 & $\left.\begin{array}{r}21 \\
5\end{array}\right\}$ & 37 & $\left.\begin{array}{c}15 \\
1\end{array}\right\}$ & 23 & $\left.\begin{array}{r}22 \\
6\end{array}\right\}$ & 40 & $\begin{array}{l}18 \text { patellectomy } \\
\text { with } 12 \text { good } \\
\text { results }\end{array}$ \\
\hline $\begin{array}{l}\text { Group B } \\
\text { (Grades 3-4) }\end{array}$ & Male & 5 & 1 & & 4 & & 0 & & 0 & & 5 & & All patellectomy \\
\hline
\end{tabular}


noted by his ship's Medical Officer to have "little in the way of symptoms attributable to chondromalacia" and has been classified as a good result. The result after one year was considered to be good if the patient was able to return to a sea-going ship or to his original athletic pursuits, even if he complained of occasional transient discomfort after heavy physical activity. Patients who had no improvement in symptoms were classified as poor results. At one year, 61 of 70 patients in Group A had a good result, giving an initial success rate of 87 per cent. Only one of the five patients in Group B gained relief.

Three years after operation an additional intermediate group could be defined. These patients had fewer symptoms than before operation but still had some limitation to their level of physical activity. These patients were classified as fair results, and have been included with the good results as having gained some improvement from operation. Review at three years showed that only 26 of the 70 patients in Group A (37 per cent) continued to have a good result from the operation. Nineteen of these 26 patients had originally had Grade 1 changes only, but all six of the patients with bipartite patella had good results. Sixteen patients from Group A ( 23 per cent) had fair results at three years in that some symptoms had returned between one and three years after operation but they had remained fit for sea service and some athletic activity. Thus, 60 per cent of Group A had some improvement as a result of operation. Twenty-eight patients from Group A (40 per cent) had poor results at three years, having relapsed. Some had undergone patellectomy and a number had been invalided from the Royal Navy as being unfit to serve at sea. Six of these patients had Outerbridge Grade 2 changes at the time of operation. All five patients in Group B had undergone patellectomy and are therefore considered to have had poor results from lateral release.

Eighteen patients with poor results from Groups $A$ and $B$ had undergone patellectomy and of these, six had unsatisfactory results. Twelve patients with good results from patellectomy were able to return to sea with a few residual symptoms.

It is interesting to note that all six patients with bipartite patellae had good results after three years. At the time of operation 29 patients were noted to have abnormally tight retinacular bands. Fourteen of these patients had good results, five were graded fair and ten had poor results. Fourteen patients with the patella displaced laterally yielded eight good, two fair and four poor results. Six patients in the whole series required lateral release of both knees although 50 originally had some symptoms on both sides. In most of these patients symptoms in the less affected knee resolved during the period of rest associated with operation on the worst knee. Of the patients who had lateral release on both knees, three had good results on both sides, two had poor results and one had a fair result.

\section{DISCUSSION}

This study indicates that lateral release can produce satisfactory results in about 60 per cent of patients with proven changes in the articular cartilage of the patella, and will allow them to continue in an employment which provides considerable stress to the knees. It is clear that the continual use of vertical ladders and climbing through hatch coamings on board ship may initiate patellar pain. Similar problems result from working in cramped compartments, especially when kneeling on a steel deck. Most of a ship's company will suffer from some aching of the knees after a period of heavy weather, when balance has to be maintained by alternation of quadriceps tension in flexed knees. This study also indicates that initially good results can deteriorate under stress, and that this is likely to occur between one and two years after operation. The cause for this is uncertain, but may be related to contracture of the scar in a less than adequate release. Ficat recommends resection of a one-centimetre wide strip of the retinaculum in an attempt to avoid this complication (Ficat, Ficat and Bailleux 1975).

The first essential in the management of patients complaining of pain in the front of the knee is the recognition and correction of causative lesions. These may include misalignment, subluxation or recurring dislocation of the patella, occult meniscal lesions, the medial plica syndrome and a bipartite patella. The latter condition may be evidence of the excess lateral pressure syndrome (Ficat and Hungerford 1977).

Our management of these patients has been progressively modified in the three years since this series of patients was treated. Investigation now includes axial radiographs taken at 30,60 and 90 degrees of flexion of the knee, and in severe cases a technetium bone scan is done which, when positive, is taken as confirmation of bony involvement. In the absence of a definite predisposing cause or a positive bone scan, conservative treatment with rest, strictly straight leg quadriceps exercises and anti-inflammatory analgesic drugs may produce symptomatic relief. Failure of conservative management is the indication for arthroscopy in order to detect occult meniscal lesions or abnormal plicae as well as to estimate the type and degree of change in the articular cartilage. Lateral release is advised early in patients with bipartite patellae or with signs of excess lateral pressure and is sometimes combined with transfer of the tibial tubercle in those few patients who have definite patellar subluxation or dislocation. A technique is then used which avoids reducing the lever arm of the patellar ligament.

Arthroscopy is performed in all cases. This is followed by the lateral release operation when patellar changes are absent or minimal (Outerbridge Grades 0,1 and 2). The incision is also a convenient approach for the open removal of a medial plica which is producing symptoms. The operation is now done through an 
eight-centimetre incision which allows better control of the line and extent of fascial release, the tying of a constant leash of vessels in the subsynovial layer and an opportunity to make a thorough assessment of the state of the articular surfaces and of the synovium (Fig. 3).

Other procedures short of patellectomy have been described. Wiles, Andrews and Devas (1956) reported fair results from the shaving of damaged articular cartilage but Bentley (1978) obtained poor results from localised excision of areas of chondromalacia. Devas and Golski (1973) treated chondromalacia by transfer of the tibial tubercle without attempting to mobilise the quadriceps apparatus by lateral release and medial reefing. Most of their patients were female and therefore predisposed to a valgus knee. Transfer of the tubercle was then a satisfactory treatment.

Chakraverty, in a Naval study, found that advancement of the tibial tuberosity with elevation of the front of the tibia by a graft from iliac crest (Maquet 1976) gave satisfactory relief of pain in five cases, but none of the patients was able to kneel for a period exceeding five minutes and all remained unfit for full sea-going duties. Merchant and Mercer (1974) published a preliminary report on 20 knees in 16 patients who underwent lateral release for symptoms of chondromalacia patellae. Seventeen of these patients had good or excellent results after one year.

This survey of 75 patients shows similar results one year after operation but many patients relapsed later, up to two years after operation. Review at three years showed no continuing deterioration and this may be significant. It is considered that lateral release is a simple procedure which does not involve the joint surfaces, or preclude other operations, such as patellectomy, at a later date. The operation may relieve patellofemoral symptoms, perhaps only temporarily unless stress on the knee is reduced, and is therefore worthy of consideration. It must be pointed out that most patients in this series were Service personnel with high standards of physical fitness, whose knees are subjected to considerable stress during their normal occupation. The operation cannot be recommended where widespread damage to articular cartilage is already present. Patellectomy would then seem to be the best procedure.

We are indebted to Surgeon Commander R. C. Telfer for permission to include his patients in this series and to Miss M. A. Nobes for typing the manuscript.

\section{REFERENCES}

Aleman O. Chondromalacia posttraumatica patellae. Acta Chir Scand 1928;63:149-90.

Bentley G. The surgical treatment of chondromalacia patellae. J Bone Joint Surg [Br] 1978;60-B:74-81.

Büdinger K. Uber traumatische knorpelrisse im Kniegelenk. Dtsch Z Chir 1908;92:510-36.

Devas M, Golski A. Treatment of chondromalacia patellae by transposition of the tibial tubercle. Br Med J 1973;i:589-91.

Ficat P, Ficat C, Bailleux A. Syndrome d'hyperpression externe de la rotule (SHPE). Rev Chir Orthop 1975;61:39-59.

Ficat RP, Hungerford DS. Disorders of the patello-femoral joint. Baltimore: Williams \& Wilkins, 1977.

Gray's Anatomy 33rd ed. Davies EU, Davies F, eds. London: Longmans Ltd, 1962:543-6.

Maquet P. Advancement of the tibial tuberosity. Clin Orthop 1976;115:225-30.

Marks KE, Bentley G. Patella alta and chondromalacia. J Bone Joint Surg [Br] 1978;60-B:71-3.

Merchant AC, Mercer RL. Lateral release of the patella: a preliminary report. Clin Orthop 1974;103:40-5.

Outerbridge RE. The etiology of chondromalacia patellae. J Bone Joint Surg [Br] 1961;43-B:752-7.

Wiles P, Andrews PS, Devas MB. Chondromalacia of the patella. J Bone Joint Surg [Br] 1956;38-B:95-113. 